\title{
Exhaled carbon monoxide is not elevated in patients with asthma or cystic fibrosis
}

\author{
W. Zetterquist*, H. Marteus*, M. Johannesson", S.L. Nordvall", E. Ihre", J.O.N. Lundberg*, \\ K. Alving*
}

Exhaled carbon monoxide is not elevated in patients with asthma or cystic fibrosis. $W$. Zetterquist, H. Marteus, M. Johannesson, S.L. Nordvall, E. Ihre, J.O.N. Lundberg, K. Alving. (C) ERS Journals Ltd 2002.

ABSTRACT: Increased levels of exhaled carbon monoxide (fractional concentration of $\mathrm{CO}$ in expired gas $(\mathrm{FE}, \mathrm{CO}))$, measured with an electrochemical sensor, have been reported in patients with inflammatory airway disorders, such as asthma, rhinitis and cystic fibrosis. This study aimed to evaluate these findings by using a fast-response nondisperse infrared (NDIR) analyser, and to compare these measurements with the fractional concentration of nitric oxide in exhaled air ( $F E, N O)$.

Thirty-two steroid-naïve asthmatics, 24 steroid-treated asthmatics (16 patients with allergic rhinitis, nine patients with cystic fibrosis), and 30 nonsmoking healthy controls were included. CO measurements with the NDIR analyser were performed simultaneously with nitric oxide (NO) analysis (chemiluminescence technique). After $15 \mathrm{~s}$ of breath-hold, single-breath exhalations over $10 \mathrm{~s}$ were performed at two flow rates and end-tidal plateau concentrations were registered. An electrochemical CO sensor was used independently with an exhalation to residual volume, after a $15 \mathrm{~s}$ breath-hold.

None of the two $\mathrm{CO}$ analysers gave a significant increase in $F \mathrm{E}, \mathrm{CO}$ in the groups of patients with inflammatory airway disorders compared to controls. FE,NO was significantly elevated in steroid-naïve asthmatics and subjects with allergic rhinitis, but not in steroid-treated asthmatics and subjects with cystic fibrosis. Reducing exhalation flow rate by $50 \%$ gave a two-fold increase in $F_{E}$,NO, while $F_{E}$,CO was unaffected. A significant increase was seen in $F E, C O$, but not in $F E, N O$, when comparing with and without a $10 \mathrm{~s}$ breath-hold.

In conclusion, the fractional concentration of carbon monoxide in expired gas was not increased in any of the patient groups, while the fractional concentration of nitric oxide in expired gas was significantly elevated in patients with steroid-naïve asthma and allergic rhinitis. Moreover, carbon monoxide was unaffected by flow rate but increased with breath-hold, suggesting an origin in the alveoli rather than the conducting airways. Eur Respir J 2002; 20: 92-99.

\begin{abstract}
*Dept of Physiology and Pharmacology, Karolinska Institutet, Stockholm, \#Dept of Woman and Child Health, Uppsala University Hospital, Uppsala and Dept of Medicine, Karolinska Hospital, Stockholm, Sweden.
\end{abstract}

Correspondence: W. Zetterquist, Dept of Physiology and Pharmacology, Karolinska Institutet, SE-171 77 Stockholm, Sweden.

Fax: 468332278

E-mail: wilhelm.zetterquist@fyfa.ki.se

Keywords: Allergic rhinitis

asthma

carbon monoxide

cystic fibrosis

exhaled air

nitric oxide

Received: May 152001

Accepted after revision: February 3 2002

This study was supported by The Swedish Research Council (grant no. 10354), The Swedish Heart and Lung Foundation, The Swedish Foundation for Health Care Science and Allergy Research, and The Swedish Asthma and Allergy Association's Research Foundation.
Ever since the first findings of increased levels of nitric oxide (NO) in the exhaled air of asthmatics [1] there has been much interest in measurements of NO in exhaled air. There are now a large number of studies supporting those original findings and consequently, NO has established itself as a marker of inflammation in the respiratory tract [2-4]. However, a few recent studies have reported elevated levels of another airborne molecule, namely carbon monoxide (CO), comma; in asthmatics and patients with other conditions associated with inflammation in the airways [5-12] and suggest that it could be yet another candidate marker of inflammation that could be measured noninvasively. Among these reports are results showing increased levels of exhaled $\mathrm{CO}$ (fractional concentration of $\mathrm{CO}$ in expired gas $(F \mathrm{E}, \mathrm{CO}))$ in patients with cystic fibrosis (CF) [8, 10], which contrasts with findings on exhaled NO (the fractional concentration of $\mathrm{NO}$ in expired gas $(F \mathrm{E}, \mathrm{NO}))[13]$, where either normal or even decreased levels have been reported [14-16]. In addition, there have even been reports of increased amounts of $\mathrm{CO}$ in the exhaled air of subjects with upper respiratory tract infections [17] and in atopic subjects without asthma [18], i.e. conditions not associated with a manifest inflammation in the lower airway mucosa.

The increase of NO production in inflamed tissues evolves from the increased expression of inducible nitric oxide synthase (iNOS) present in inflammatory cells and epithelial cells. In the respiratory epithelium of asthmatics, for example, there is a marked increase in the expression of iNOS [19]. With regard to CO, there is a well-known diffusion of $\mathrm{CO}$ from the bloodstream to alveolar air, and, hence, an obvious alveolar origin of $F \mathrm{E}, \mathrm{CO}$. However, it has been argued that the possible increase in CO production in asthma, and other states of inflammation in the respiratory tract, could have its origin in the respiratory 
epithelium of the bronchi through an induction of the enzyme haeme oxygenase (HO-1) [7]. This induction of $\mathrm{HO}-1$ would be a reaction to oxidative stress, which is believed to play an important role in the pathogenesis of many diseases, including chronic inflammatory lung disorders [7, 20]. HO-1 catalyses the initial step in the oxidative degradation of haeme to bilirubin, a reaction which also yields a molecule of $\mathrm{CO}$. Bilirubin is an antioxidant in itself and $\mathrm{CO}$ has, among other biological activities, the ability to stimulate guanylate cyclase, and thus HO-1 induction could serve a protective role against oxidant-mediated cell injury [21]. However, contrary to the case with iNOS, there are as yet no convincing studies that show an actual increase in the expression of HO-1 in inflammatory airway disorders [22].

The possible advantage of using $\mathrm{CO}$ in exhaled air as a marker of inflammation is that it is found in much higher concentrations than NO. CO concentrations in exhaled air amounts to parts per million (ppm), whereas NO is usually detectable only as parts per billion (ppb), which would allow for less sophisticated and expensive analysers when measuring $\mathrm{CO}$ in the airways. In previous studies on $\mathrm{CO}$ in exhaled air, electrochemical sensors, designed as tools for smoking cessation, have been used [5-12, 17, 18]. Conversely, cigarette smoke and possibly even other forms of pollution, such as car exhausts, give elevated levels of $F$ E,CO and this would clearly be a major disadvantage to using $\mathrm{CO}$ as an inflammatory marker.

The aim of this study was to investigate whether the reports of increased levels of $F \mathrm{E}, \mathrm{CO}$ in patients with inflammatory airway diseases were reproducible in a group of asthmatics, both steroid- and nonsteroidtreated, a group of patients with allergic rhinitis, and a group of CF patients. A fast-response, nondisperse infrared (NDIR) CO analyser was used alongside an electrochemical sensor. The authors also wanted to relate levels of $F \mathrm{E}, \mathrm{CO}$ to measurements of $F \mathrm{E}, \mathrm{NO}$, as $F$ E,NO is a more established marker of airway inflammation. Since there is a well-documented flow dependency of NO concentrations in exhaled air, supporting a bronchial origin of $\mathrm{NO}[23,24], \mathrm{CO}$ measurements were also performed at different exhalation flow rates to see whether this would also hold true for CO. To further clarify the origin of the two gases, i.e. bronchial or alveolar, $\mathrm{CO}$ and $\mathrm{NO}$ were registered after breath-hold, as the end-tidal plateau concentrations should increase after breath-hold if the molecule mainly comes from the alveoli and remain unaffected if the production is in the bronchi. Finally, a cigarette smoke experiment was performed to see the effects on the levels of $F$ E,CO and FE,NO.

\section{Materials and methods}

The study was approved by the local ethics committee.

\section{Subjects}

The comparative study of $F$ E,CO and FE,NO was performed on 32 steroid-naïve asthmatics (8-57 yrs,
19 females), 24 steroid-treated asthmatics (12-64 yrs, 11 females), 16 subjects with allergic rhinitis (10-61 yrs, seven females), nine subjects with CF (7-32 yrs, six females) and 30 nonsmoking healthy controls (13-45 yrs, 12 females).

Asthmatic subjects were recruited through the Lung and Allergy Clinic of Karolinska Hospital (Stockholm, Sweden), the Allergy section of the Paediatric Clinic of Uppsala University Hospital (Uppsala, Sweden), and The Swedish Asthma and Allergy Association (Stockholm, Sweden). They all had a history of asthma symptoms, either as a consequence of allergen exposure or of nonallergic airway hyperreactivity. Apart from their symptoms, they had all shown a significant reversibility of their forced expiratory volume in one second (FEV1) and midexpiratory flow rates, as measured with a spirometer, upon treatment with bronchodilators (i.e. $\beta_{2}$-agonists) before receiving the asthma diagnosis. Almost half of the subjects $(n=14)$ in the group of steroid-naïve asthmatics had a record of mild and quite intermittent symptoms and were not affected by their disease at the time of the experiment. The remaining subjects in this group of untreated asthmatics had more frequent or even persistent symptoms of wheeze and cough. The steroid-treated asthmatics generally had a history of more persistent or disabling asthma, but, due to their treatment, they were now more or less free of symptoms. The subjects with allergic rhinitis all had a record of recurring rhinoconjunctivitis without any symptoms from the bronchi and were, with two exceptions, recruited from the two allergy clinics mentioned above, where they were undergoing immunotherapy (i.e. hyposensitisation) against relevant allergen. These patients had all performed normal spirometries with no signs of reversibility upon treatment with $\beta_{2}$-agonists. None of them had any current symptoms of rhinitis. The patients with $\mathrm{CF}$ were all outpatients at the Paediatric Clinic of Uppsala University Hospital (Uppsala, Sweden) and had well-documented disease, generally diagnosed during the first year of life. All of them were colonised with Pseudomonas and/or Staphylococci bacteria but were not receiving any antibiotics at the time of the study, and were not, therefore, considered to be in an exacerbated state. Two of the CF patients were on treatment with inhaled steroids; the others were treated with only bronchodilators and expectorants.

The patients and healthy controls were included in the study after informed consent was obtained.

\section{Measurements of carbon monoxide and nitric oxide in exhaled air}

The registrations of $F$ E,CO were performed with two different measuring techniques, as mentioned above; an electrochemical sensor (Bedfont EC50 Mini-Smokerlyzer; Bedfont Scientific, Kent, UK) and a fast-response NDIR analyser (UNOR 610; Maihak AG, Hamburg, Germany). The former is a small and simple unit, used mainly as a device for smoking cessation, with a detection limit of $1 \mathrm{ppm}$ and without a signal output feature. Computer 
analysis of the detected CO levels was therefore not possible. The NDIR analyser, however, with a response time of $<3 \mathrm{~s}$ and a detection limit of $0.1 \mathrm{ppm}$, allowed on-line measurements to be taken, which could be incorporated into the normal computer set-up for NO analysis (see below), providing figures for flow rate together with concentration curve profiles.

The procedure for taking measurements with the Bedfont EC50 was as described in previously published reports and in the guidelines from the manufacturer. Thus, the subjects inhaled room air to total lung capacity (TLC), followed by a $15 \mathrm{~s}$ breath-hold before making an exhalation into the mouthpiece of the analyser. There was no time set for the exhalation and the airflow was not registered. Instead, the subjects were asked to make a full exhalation to residual volume. The top value, given with a 10-20 s delay as ppm (no decimals), was then registered as the subject's CO concentration of the airways. The analyser was calibrated against a gas with a known $\mathrm{CO}$ concentration of $16 \mathrm{ppm}$ and $\mathrm{CO}$-free air (see below).

The fast-responding analogue signal output from the NDIR analyser enabled it to be incorporated into the computer set up for NO measurements. Thus, the on-line measurements of $\mathrm{CO}$ were performed simultaneously with registrations of NO concentration, using the same exhaled air. NO was measured with a chemiluminescence analyser (CLD 77 AM; Eco Physics, Dürnten, Switzerland). The two analysers were calibrated and continuously fed with both NOand $\mathrm{CO}$-free air from a nondiffusing gas collection bag (Hans Rudolph, Kansas, MO, USA). The purified air was obtained by connecting a cylinder with Medical Breathing Air (AGA AB, Stockholm, Sweden) to a Purafill drypowder scrubber and, to remove $\mathrm{CO}$, an electronic scrubber (Alphagaz Air Flow; Air Liquide Gas AB, Kista, Sweden) in presequence to the gas collection bag. However, the ambient $\mathrm{CO}$ levels were $<1 \mathrm{ppm}$ during all study sessions. The gas collection bag was in the inhalation limb and further connected to a Y-piece with two one-way valves, which in turn was adapted to a mouthpiece. As a standard procedure, the subjects were instructed to inhale the NO- and CO-free air from the gas collection bag to TLC, hold their breath for $15 \mathrm{~s}$, and exhale against a resistance at a constant flow rate for $10 \mathrm{~s}$. The flow rates were set to $0.15 \mathrm{~L} \cdot \mathrm{s}^{-1}$ and $0.075 \mathrm{~L} \cdot \mathrm{s}^{-1}$, with the same oral pressure of $8-10 \mathrm{cmH}_{2} \mathrm{O}$ (this pressure was used for all exhalations in the study), using linear resistances of 50 and $100 \mathrm{cmH}_{2} \mathrm{O} \cdot \mathrm{L}^{-1} \cdot \mathrm{s}$ (Hans Rudolph), respectively. The exhaled air exited through the other one-way valve in the Y-piece, which lead to a linear pneumotachymeter (Hans Rudolph) where flow and pressure were registered. Fractions of the exhaled air were sampled into the analysers for $\mathrm{CO}$ and $\mathrm{NO}$ at a flow rate of $0.5 \mathrm{~L} \cdot \mathrm{min}^{-1}$ and $0.1 \mathrm{~L} \cdot \mathrm{min}^{-1}$, respectively, through two different narrow-bore tubes connected close to the mouthpiece. The signals from the two analysers and the pneumotachymeter were fed into a computer, processed by a software program (Exhaled Breath Analyser; Aerocrine AB, Stockholm, Sweden) and visualised as curves in real time on the computer screen. They showed the CO and NO concentrations for every part of the breath together with a curve for the flow rate, with the latter enabling the subjects to maintain a certain flow by adjusting the exhalation to a given range. Calculated mean values of the $\mathrm{CO}$ and NO concentrations were presented for the last $40 \%$ of the exhalation, representing the plateau phase (with a slope of $<10 \%$ ). Each subject made two exhalations at $0.15 \mathrm{~L} \cdot \mathrm{s}^{-1}$ and $0.075 \mathrm{~L} \cdot \mathrm{s}^{-1}$, respectively, and the mean values of these were used for each flow rate.

\section{Carbon monoxide measurements at a series of different flow rates}

Eight healthy nonsmoking subjects (25-40 yrs, three females) were instructed to exhale at four different flow rates, $0.05 \mathrm{~L} \cdot \mathrm{s}^{-1}, 0.1 \mathrm{~L} \cdot \mathrm{s}^{-1}, 0.2 \mathrm{~L} \cdot \mathrm{s}^{-1}$, and $0.5 \mathrm{~L} \cdot \mathrm{s}^{-1}$, using resistances of $20,50,100$, and $200 \mathrm{cmH} \mathrm{O}_{2} \mathrm{O} \cdot \mathrm{L}^{-1} \cdot \mathrm{s}$, respectively, after a previous breath-hold of $15 \mathrm{~s}$. The measurements were performed with the NDIR analyser only.

\section{Carbon monoxide and nitric oxide measurements with and without breath-hold}

The same eight subjects were also asked to perform a series of exhalations after a breath-hold of $10 \mathrm{~s}, 20 \mathrm{~s}$ and $40 \mathrm{~s}$, at a flow rate of $0.15 \mathrm{~L} \cdot \mathrm{s}^{-1}$, as well as one measurement without a breath-hold. Only the NDIR analyser was used for $\mathrm{CO}$ concentrations.

\section{Carbon monoxide and nitric oxide measurements after smoking one cigarette}

The effect of cigarette smoking was examined in the same eight subjects. Baseline values were obtained for $F \mathrm{E}, \mathrm{CO}$ and $F \mathrm{E}, \mathrm{NO}$, with the former measured by both analysers, after a $15 \mathrm{~s}$ breath-hold. Exhalation flow rate was set to $0.15 \mathrm{~L} \cdot \mathrm{s}^{-1}$ for $\mathrm{NO}$ and for $\mathrm{CO}$, measured with the NDIR analyser. The subjects then smoked one cigarette each (Marlboro Lights; Philip Morris Inc., Richmond, VA, USA) and measurements were repeated after 1,10 and $30 \mathrm{~min}$.

\section{Analysis}

All values are presented as mean \pm SEM, except for box and whisker plots, where whiskers show the range and boxes show the 25th, 50th (median), and 75th percentiles. The values for $\mathrm{CO}$ and NO concentrations were calculated as the mean of two consecutive measurements at all times and each flow rate. The mean values for $\mathrm{CO}$ and $\mathrm{NO}$ concentrations for each of the different groups were analysed using the nonparametric Mann-Whitney U-test. Changes in $\mathrm{CO}$ and NO values after increasing breath-hold and after cigarette smoking, as well as for changes in $\mathrm{CO}$ with increasing flow rates, were analysed by the nonparametric Wilcoxon signed rank test for paired measurements. 


\section{Results}

Carbon monoxide and nitric oxide in patients with asthma, allergic rhinitis and cystic fibrosis

Compared to controls, no significant increase was found in levels of $F \mathrm{E}, \mathrm{CO}$ among the subjects with allergic rhinitis $(\mathrm{p}=0.46)$, steroid-naïve asthma $(\mathrm{p}=$ $0.74)$, steroid-treated asthma $(\mathrm{p}=0.75)$ or $\mathrm{CF}(\mathrm{p}=0.82$; all $\mathrm{p}$-values were obtained using the NDIR UNOR 610 analyser) (fig. 1). The lack of significantly elevated

a)

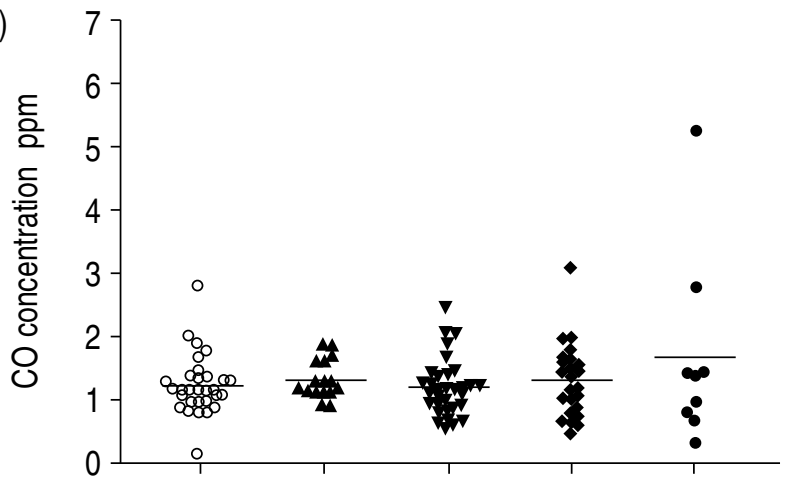

b)

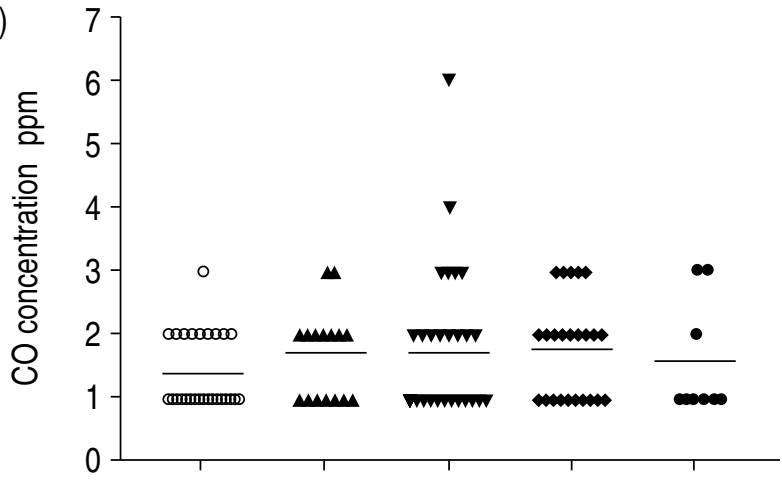

c)

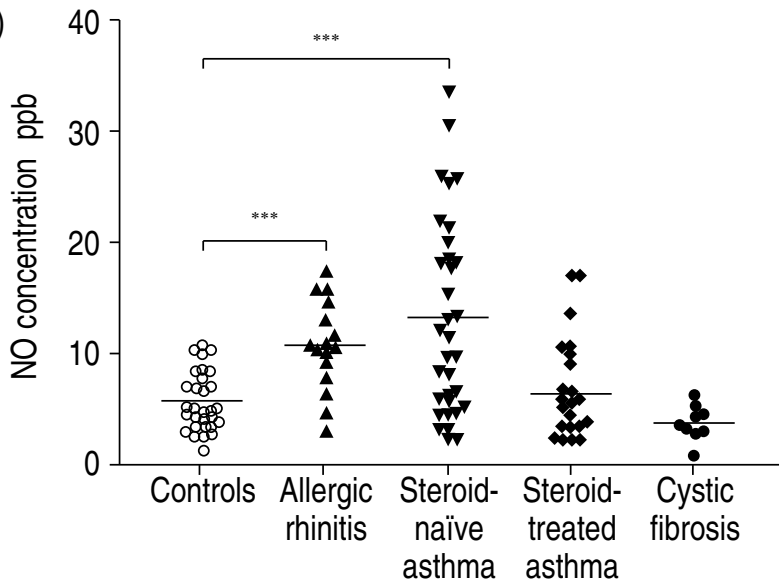

Fig. 1.-Concentrations of exhaled carbon monoxide (CO) and nitric oxide (NO) in subjects with allergic rhinitis, steroid-naïve asthma, steroid-treated asthma and cystic fibrosis compared to healthy controls. a) $\mathrm{CO}$ levels in parts per million (ppm) as measured with the fast-response nondisperse infrared analyser at an exhalation flow rate of $0.15 \mathrm{~L} \cdot \mathrm{s}^{-1}$, and b) with the electrochemical sensor at unknown flow rates. c) NO concentrations in parts per billion (ppb) at exhalation flow rate of $0.15 \mathrm{~L} \cdot \mathrm{s}^{-1}$. ***: $\mathrm{p}<0.001$ compared to controls.
$\mathrm{CO}$ concentrations held true for both $\mathrm{CO}$ analysers, i.e. the Bedfont EC50 analyser and the NDIR UNOR 610 analyser. However, the levels of $F \mathrm{E}$,NO were significantly elevated for both patients with allergic rhinitis $(\mathrm{p}<0.001)$ and steroid-naïve asthma $(\mathrm{p}<0.001)$ compared to controls, whereas steroid-treated asthmatics showed no significant increase $(\mathrm{p}=0.958)$. In patients with $\mathrm{CF}$, there was a statistical trend towards lower NO concentrations compared to controls $(\mathrm{p}=0.067)$ (fig. 1). This outcome was obtained with both flow rates, but figure 1 only presents the concentrations from the $0.15 \mathrm{~L} \cdot \mathrm{s}^{-1}$.

Carbon monoxide measurements with different flow rates

No significant differences in the $\mathrm{CO}$ concentrations could be seen in the exhaled air of the eight healthy controls, as the exhalation flow rates were altered from $0.05,0.1,0.2$ to $0.5 \mathrm{~L} \cdot \mathrm{s}^{-1}$ (fig. 2).

In addition, no significant differences in the $\mathrm{CO}$ concentrations were registered when measuring from the subjects with allergic rhinitis, asthma or $\mathrm{CF}$ and altering the flow rate from $0.15 \mathrm{~L} \cdot \mathrm{s}^{-1}$ to $0.075 \mathrm{~L} \cdot \mathrm{s}^{-1}$. Conversely, the NO concentrations were, as expected, increased by $\sim 100 \%$ in all the groups when flow rate was changed from $0.15 \mathrm{~L} \cdot \mathrm{s}^{-1}$ to $0.075 \mathrm{~L} \cdot \mathrm{s}^{-1}$. Figure 3 shows the results of altering flow rate in steroid-naïve asthmatics and patients with $\mathrm{CF}$.

\section{Carbon monoxide and nitric oxide measurements after breath-hold}

The plateau concentrations of $\mathrm{CO}$ in the exhaled air of the eight healthy controls increased by $\sim 80 \%$ $(\mathrm{p}<0.01)$ when they held their breath for $10 \mathrm{~s}$, as compared to exhaling without breath-hold. However, compared to the $10 \mathrm{~s}$ breath-hold, there was no additional increase in the $\mathrm{CO}$ concentrations when the breath-hold was extended to 20 and $40 \mathrm{~s}$. No significant differences in the end-tidal plateau concentrations of $\mathrm{NO}$ were registered when comparing

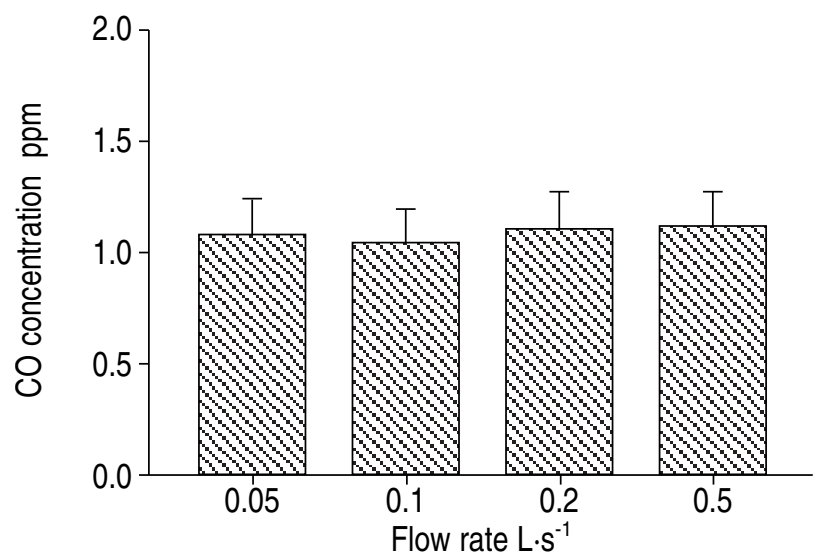

Fig. 2.-Concentrations of exhaled carbon monoxide (CO) at different flow rates in eight healthy nonsmoking controls. ppm: parts per million. 
a)

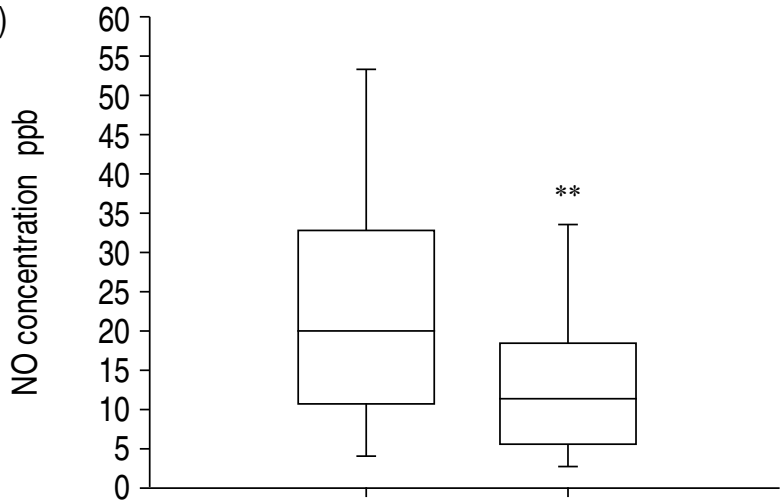

c)

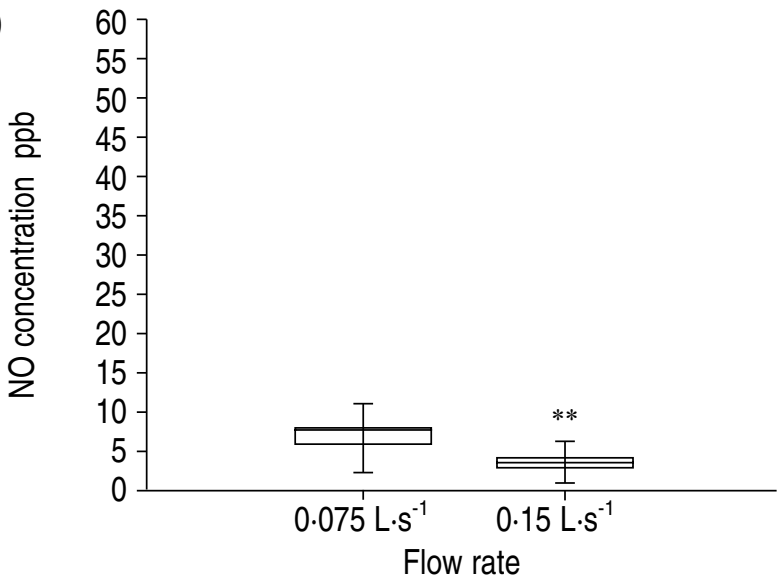

b)

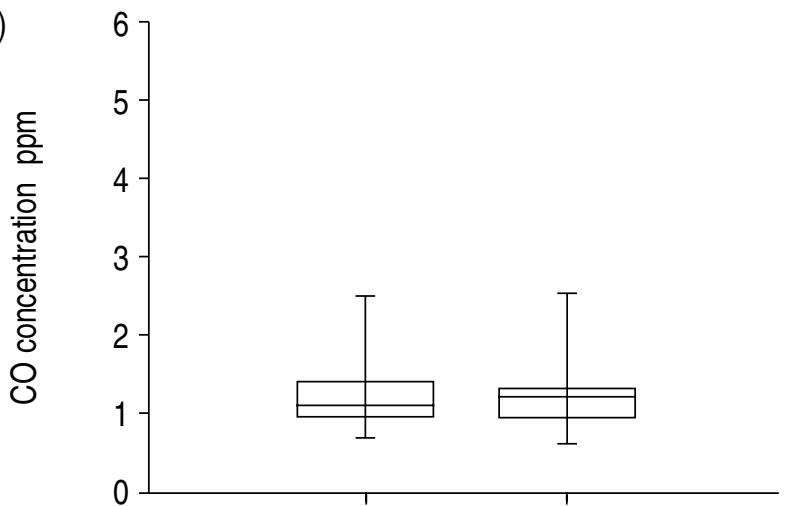

d)

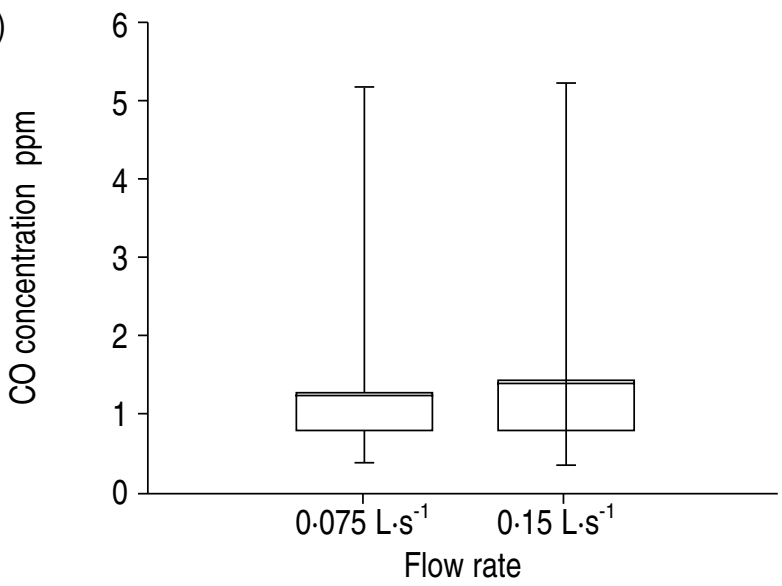

Fig. 3.-Comparison of two different flow rates and their influence on the concentrations of exhaled carbon monoxide (CO) and nitric oxide (NO) in subjects with a) and b) steroid-naïve asthma $(n=32)$ and c) and d) cystic fibrosis $(n=9)$. ppm: parts per million; ppb: parts per billion.

the measurements in exhaled air without previous breath-hold to those with a breath-hold of 10, 20 and $40 \mathrm{~s}$ (fig. 4). However, an initial NO peak was seen after breath-hold, with a magnitude that increased with increased breath-hold time (not shown). Conversely, such an initial peak in $\mathrm{CO}$ concentration was never seen.

Carbon monoxide and nitric oxide measurements after cigarette smoking

The levels of FE,CO showed a three-fold increase $(\mathrm{p}<0.01) 1 \mathrm{~min}$ after smoking one cigarette, as shown by both of the $\mathrm{CO}$ analysers. Although a slight decrease after 10 and 30 min was seen, the concentrations remained significantly elevated, whereas for the NO concentrations, no significant changes could be seen acutely after cigarette smoking (fig. 5).

\section{Discussion}

Several recent studies have reported elevated $\mathrm{CO}$ concentrations in the exhaled air of patients with inflammatory airway disorders, both in more chronic ones, such as asthma, allergic rhinitis, CF, and bronchiectasis [5-12, 18], as well as in the more temporary condition of an upper respiratory tract infection [17].
$\mathrm{CO}$ has therefore been proposed as a possible marker of inflammation in the airways. The idea that $\mathrm{CO}$ levels might be elevated by inflammatory activity comes form the notion of oxidative stress, where $\mathrm{CO}$ is known to be one of the end products of the action of the enzyme HO-1 [21]. Some evidence that oxidative stress plays a role in pulmonary diseases has been presented $[6,20]$, but the results of studies looking at increases of HO-1 in airway epithelium or inflammatory cells in patients with inflammatory airway disorders have been controversial [7, 22].

However, unlike previous studies, the present authors could not find any significantly elevated levels of $\mathrm{CO}$ in the exhaled air of the subjects with asthma, allergic rhinitis or CF. This was true for both measuring techniques, even when using the same analyser and measuring technique that has been described in the previous reports. The results from the NDIR analyser, introduced here, corresponded very well with the values obtained with the electrochemical sensor. Linear regression analysis was not possible, however, because of the discrete numbers given by the electrochemical sensor, clustering at one or two measuring values, compared to the spread of decimal values given by the NDIR analyser.

In contrast to the absence of altered $\mathrm{CO}$ values, significantly elevated NO levels in the exhaled air of steroid-naïve asthmatics and in the subjects with 
a)

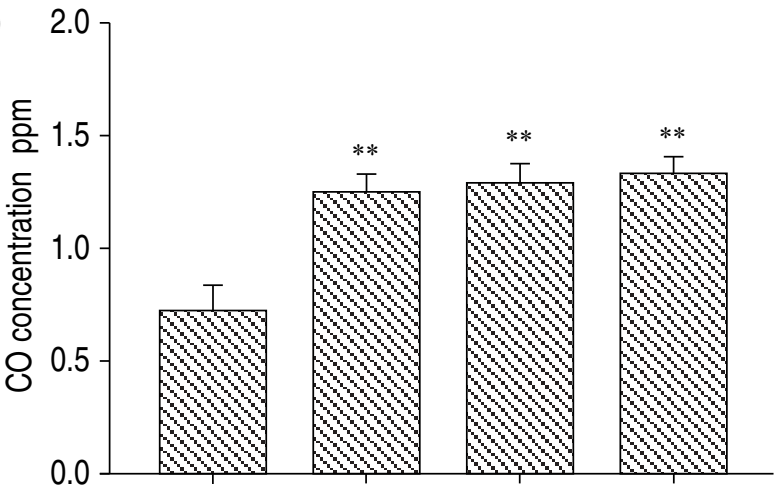

b)

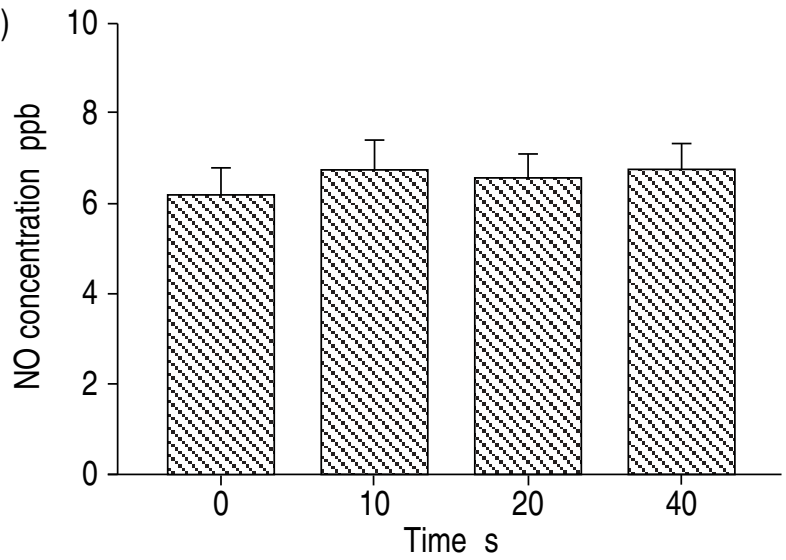

Fig. 4. - Influence of increasing lengths of breath-hold on concentrations of a) exhaled carbon monoxide (CO) and b) exhaled nitric oxide (NO) in eight healthy nonsmoking subjects, as compared to exhalation without previous breath-hold $(0 \mathrm{~s}) . \mathrm{ppm}$ : parts per million; ppb: parts per billion. ${ }^{* *}$ : $\mathrm{p}<0.01$.

allergic rhinitis were found, which is in line with previous studies [1-4]. Asthma and allergic rhinitis are two conditions with elevated inflammatory activity in the airways and, again, this shows that NO is a sensitive marker of airway inflammation. Patients with $\mathrm{CF}$ showed rather decreased levels of $F \mathrm{E}, \mathrm{NO}$, which could be due to an impaired diffusion of NO from the mucus membrane to the airway lumen, a deficient epithelial NO production, or simply less contamination of nasal NO, which is well known to be markedly reduced in these patients $[14,16,25]$.

Another finding that questions the presence and inflammatory induction of $\mathrm{CO}$ in the conducting airways is the lack of flow dependency when measuring $F$ E,CO. In this study, there were no significant alterations of the $\mathrm{CO}$ concentrations when changing the flow rates in any of the groups with airway disorders, and not even when the healthy controls altered the flow rate 10 -fold. This strongly indicates that there is no contribution of $\mathrm{CO}$ from the airway epithelium, since the $\mathrm{CO}$ concentrations would then increase with a decreased flow of exhaled air. As expected, however, a close relationship between flow rates and NO values was seen, where a two-fold increase in flow rate gave an approximate 50\% reduction in the NO concentrations, thus, clearly indicating an airway origin of NO.

Since there seems to be no contribution of $\mathrm{CO}$ from
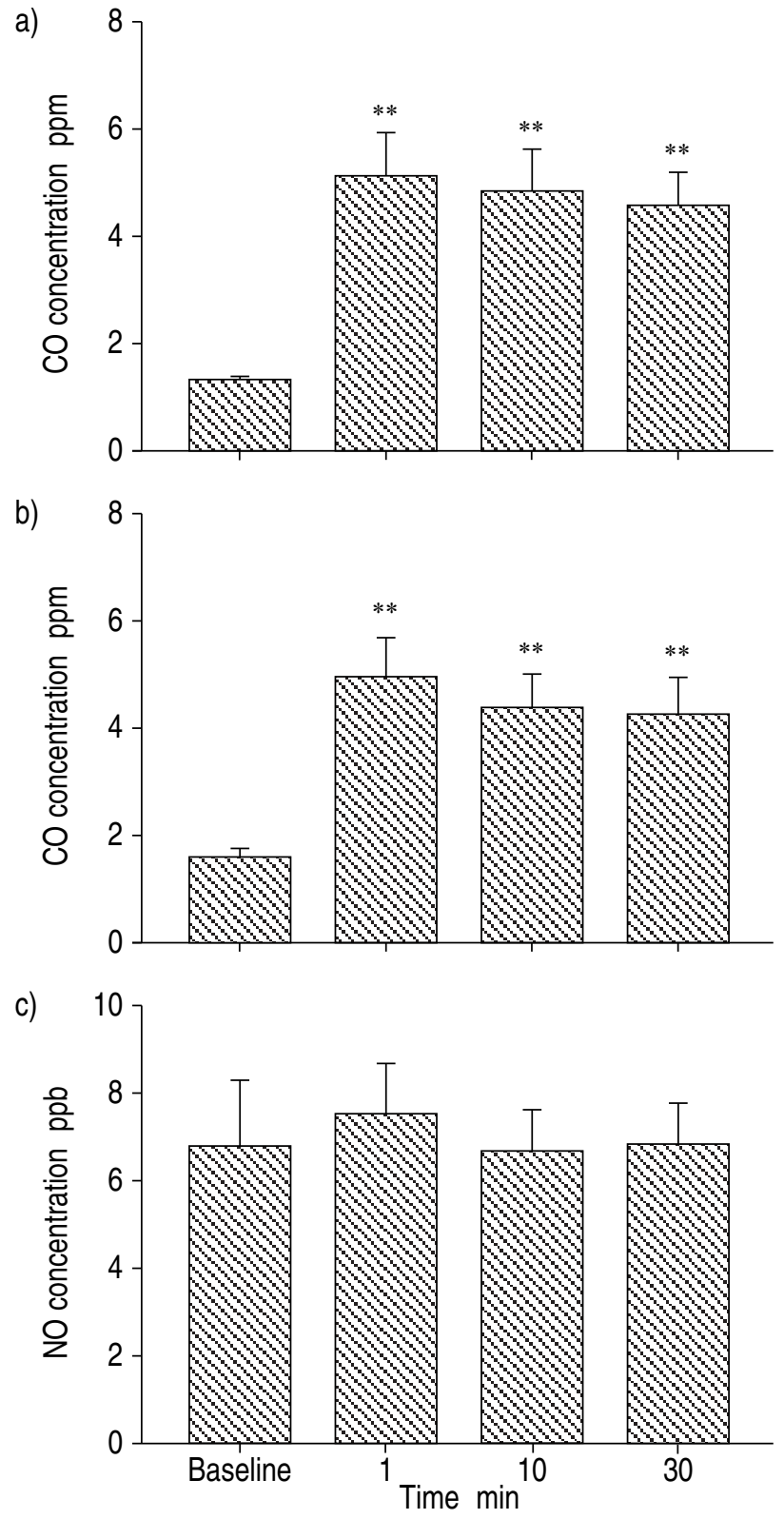

Fig. 5.-Effects of smoking one cigarette on exhaled concentrations of carbon monoxide (CO) and nitric oxide (NO) in eight healthy, nonsmoking subjects. Measurements performed 1, 10 and 30 min after smoking the cigarette, with a 15-s breath-hold before exhalation. a) $\mathrm{CO}$ concentrations in parts per million (ppm) as registered by the fast-response nondisperse infrared analyser at exhalation flow rate $0.15 \mathrm{~L} \cdot \mathrm{s}^{-1}$, and b) with the electrochemical sensor at unknown flow rate. c) NO concentrations in parts per billion (ppb) at exhalation flow rate of $0.15 \mathrm{~L} \cdot \mathrm{s}^{-1}$. $* *$ : $\mathrm{p}<0.01$.

the conducting airways it must have its origin in the alveoli. Support for this is also given by the increase in $\mathrm{CO}$ concentrations after breath-hold. The increase was seen when comparing an exhalation after a short breath-hold of $10 \mathrm{~s}$ with an exhalation without any previous breath-hold. During these $10 \mathrm{~s}$, a diffusion of $\mathrm{CO}$ from the microcirculation in the alveoli occurs and affects the amount of $\mathrm{CO}$ exhaled. However, it seems that equilibrium between alveolar gas and blood is established during these first $10 \mathrm{~s}$, since no further change is seen with increased breath-hold 
times. A standardised time of breath-hold of $15 \mathrm{~s}$ was used in all the experiments reported here, which should have been sufficient for equilibrium to take place. In accordance with previous findings [26], it was found that applying a breath-hold to the NO measurements produced a large initial peak of NO, but the plateau values were never affected. The initial peak increased with increasing time of breath-hold, which also indicates that NO comes almost exclusively from the conducting airways and not the alveoli. This initial peak was never seen when measuring CO, which again questions an airway origin of $\mathrm{CO}$.

One clear disadvantage of using $\mathrm{CO}$ as an airborne marker of airway disease is the huge impact of cigarette smoke and possibly other air pollution on the measurements. Smoking one cigarette gave more than a three-fold increase in the $\mathrm{CO}$ concentrations and the effect was sustained for $>30 \mathrm{~min}$, whereas $F$ E,NO concentrations were not affected. Passive smoking and exposure to polluted ambient air were never tested but it can be speculated that they could be a possible source of error. In the current authors' laboratory there was never more than $1 \mathrm{ppm}$ of $\mathrm{CO}$ in the ambient air, and when using the NDIR analyser, the subjects even inhaled CO-free air from the gas collection bag before exhaling. In previous studies on $F$ E,CO ambient levels were not reported. Is it possible that high ambient levels of $\mathrm{CO}$ could affect patients with respiratory disease more? Previous reports suggest that $F$ E,CO levels show a negative correlation with FEV1 $[9,12]$. Since it has also been shown that decreased FEV1 can give impaired gas diffusion [27], this negative correlation between $\mathrm{CO}$ and FEV1 could be an effect of trapped $\mathrm{CO}$ in the patients with respiratory disorders. Thus, is it that these patients have an impaired ability, compared to healthy controls, to ventilate themselves free of haemoglobinbound $\mathrm{CO}$ after $\mathrm{CO}$ exposure? This notion has been supported in a preliminary study [28]. Furthermore, in another very recent study, increased levels of $F$ E,CO were seen only in subjects with severe unstable asthma, while other asthmatics had normal levels [12]. This implies that it requires a more impaired lung function to produce increased $\mathrm{CO}$ levels, when a negative effect on gas diffusion is more likely.

Studying $F$ E,CO and $F$ E,NO poses another question. How could ppm levels of $\mathrm{CO}$ be obtained from HO-1 induction in the airway epithelium, when iNOS induction only gives rise to ppb levels? Especially since an elevated expression of iNOS has been found superficially in the epithelium of asthmatics [19] and there are no convincing reports of similar $\mathrm{HO}-1$ induction [22]. The only increase of HO-1 that has been reported from an inflammatory airway disorder is elevated expression in macrophages retrieved from the airways of asthmatics [7]. However, an increase in the expression of the enzyme in one or two types of inflammatory cells in the lumen could not give the same surface for diffusion as if it was expressed superficially in the epithelium. It could be argued that $\mathrm{NO}$ is more rapidly taken up by the pulmonary circulation [29, 30], but this does not answer the question since $\mathrm{NO}$ is released from the conducting airways during a single-breath exhalation, and NO is not taken up in the dead space area [29]. Another argument could be that NO is rapidly consumed with a short half-life. But this is only true of NO in the liquid phase, and NO diffuses rapidly into the gas-phase [31], where it is very stable at low concentrations [32]. Thus, a major contribution of $\mathrm{CO}$ from the alveoli, with their large total surface area, seems to be the only explanation for this discrepancy.

In summary, this study has shown no significant increase in the concentration of carbon monoxide in expired gas in patients with either steroid-naïve or steroid-treated asthma, or in patients with allergic rhinitis or $\mathrm{CF}$, as compared to controls, regardless of the use of two different measuring techniques. However, in the same subjects, elevated levels of the concentration of nitric oxide in expired gas were found in the groups of steroid-naïve asthmatics and subjects with allergic rhinitis. The experiments have shown further that the concentration of carbon monoxide in expired gas is greatly affected by cigarette smoke and possibly by pollution from fuelled hydrocarbons in general. Finally, it was illustrated that the concentration of carbon monoxide in expired gas is unaffected by alterations in flow rate, but increases with breath-hold, in contrast to nitric oxide, which strongly indicates an alveolar origin of carbon monoxide and questions its presence and importance in the airways and its usefulness as a marker of airway inflammation.

\footnotetext{
Acknowledgements. The authors would like to thank H. Sasaki, M. Yamaya, and T. Ohrui (Dept of Geriatric Medicine, Tohoko University School of Medicine, Sendai, Japan) for kindly lending their electrochemical sensor for carbon monoxide measurements (Bedfont EC50 Mini-Smokerlyzer; Bedfont Scientific, Kent, UK) and thereby enabling this study to get started. They would also like to thank P. Wennerholm and C. Pedroletti for practical help with the experiments.
}

\section{References}

1. Alving K, Weitzberg E, Lundberg JM. Increased amount of nitric oxide in exhaled air of asthmatics. Eur Respir J 1993; 6: 1368-1370.

2. Barnes PJ, Kharitonov SA. Exhaled nitric oxide: a new lung function test. Thorax 1996; 51: 233-237.

3. Lundberg JO, Weitzberg E, Lundberg JM, Alving K. Nitric oxide in exhaled air. Eur Respir J 1996; 9: 26712680.

4. Kharitonov SA, Barnes PJ. Clinical aspects of exhaled nitric oxide. Eur Respir J 2000; 16: 781-792.

5. Zayasu K, Sekizawa K, Okinaga S, Yamaya M, Ohrui $\mathrm{T}$, Sasaki H. Increased carbon monoxide in exhaled air of asthmatic patients. Am J Respir Crit Care Med 1997; 156: 1140-1143.

6. Horvath I, Loukides S, Wodehouse T, Kharitonov SA, Cole PJ, Barnes PJ. Increased levels of exhaled carbon monoxide in bronchiectasis: a new marker of oxidative stress. Thorax 1998; 53: 867-870.

7. Horvath I, Donnelly LE, Kiss A, Paredi P, Kharitonov 
SA, Barnes PJ. Raised levels of exhaled carbon monoxide are associated with an increased expression of heme oxygenase-1 in airway macrophages in asthma: a new marker of oxidative stress. Thorax 1998; 53: 668-672.

8. Paredi P, Shah PL, Montuschi P, et al. Increased carbon monoxide in exhaled air of patients with cystic fibrosis. Thorax 1999; 54: 917-920.

9. Paredi P, Leckie MJ, Horvath I, Allegra L, Kharitonov SA, Barnes PJ. Changes in exhaled carbon monoxide and nitric oxide levels following allergen challenge in patients with asthma. Eur Respir J 1999; 13: 48-52.

10. Antuni JD, Kharitonov SA, Hughes D, Hodson ME, Barnes PJ. Increase in exhaled carbon monoxide during exacerbations of cystic fibrosis. Thorax 2000; 55: $138-142$.

11. Uasuf CG, Jatakanon A, James A, Kharitonov SA, Wilson NM, Barnes PJ. Exhaled carbon monoxide in childhood asthma. J Pediatr 1999; 135: 569-574.

12. Yamaya M, Hosoda M, Ishizuka S, et al. Relation between exhaled carbon monoxide levels and clinical severity of asthma. Clin Exp Allergy 2001; 31: 417422.

13. Anonymous. American Thoracic Society official statement: Recommendations for standardized procedures for the online and offline measurement of exhaled lower respiratory nitric oxide and nasal nitric oxide in adults and children - 1999. Am J Respir Crit Care Med 1999; 160: 2104-2117.

14. Grasemann H, Michler E, Wallot M, Ratjen F. Decreased concentration of exhaled nitric oxide (NO) in patients with cystic fibrosis. Pediatr Pulmonol 1997; 24: 173-177.

15. Ho LP, Innes JA, Greening AP. Exhaled nitric oxide is not elevated in the inflammatory airways diseases of cystic fibrosis and bronchiectasis. Eur Respir J 1998; 12: $1290-1294$.

16. Lundberg JO, Nordvall SL, Weitzberg E, Kollberg H, Alving K. Exhaled nitric oxide in paediatric asthma and cystic fibrosis. Arch Dis Child 1996; 75: 323-326.

17. Yamaya M, Sekizawa K, Ishizuka S, Monma M, Mizuta K, Sasaki H. Increased carbon monoxide in exhaled air of subjects with upper respiratory tract infections. Am J Respir Crit Care Med 1998; 158: 311-314

18. Horvath I, Barnes PJ. Exhaled monoxides in asymptomatic atopic subjects. Clin Exp Allergy 1999; 29: 1276-1280.

19. Hamid Q, Springall DR, Riveros-Moreno V, et al. Induction of nitric oxide synthase in asthma. Lancet 1993; 342: 1510-1513.

20. Repine JE, Bast A, Lankhorst I. Oxidative stress in chronic obstructive pulmonary disease. Oxidative Stress Study Group. Am J Respir Crit Care Med 1997; 156: 341-357.

21. Choi AM, Alam J. Heme oxygenase-1: function, regulation, and implication of a novel stress-inducible protein in oxidant-induced lung injury. Am J Respir Cell Mol Biol 1996; 15: 9-19.

22. Lim S, Groneberg D, Fischer A, et al. Expression of heme oxygenase isoenzymes 1 and 2 in normal and asthmatic airways. Effect of inhaled corticosteroids. Am J Respir Crit Care Med 2000; 162: 1912-1918.

23. Silkoff PE, McClean PA, Slutsky AS, et al. Marked flow-dependence of exhaled nitric oxide using a new technique to exclude nasal nitric oxide. Am J Respir Crit Care Med 1997; 155: 260-267.

24. Kroesbergen A, Jobsis Q, Bel EH, Hop WC, de Jongste JC. Flow-dependency of exhaled nitric oxide in children with asthma and cystic fibrosis. Eur Respir $J$ 1999; 14: 871-875.

25. Balfour-Lynn IM, Laverty A, Dinwiddie R. Reduced upper airway nitric oxide in cystic fibrosis. Arch Dis Child 1996; 75: 319-322.

26. Persson MG, Wiklund NP, Gustafsson LE. Endogenous nitric oxide in single exhalations and the change during exercise. Am Rev Respir Dis 1993; 148: 1210-1214.

27. Lennon PF, Schulman LL, Enson Y. Effect of chronic airways obstruction on measurement of the singlebreath carbon-monoxide-diffusing capacity. Respiration 1987; 52: 171-180.

28. Antuni JD, Ward S, Cramer D, Kharitonov SA, Barnes PJ. Uptake and elimination of exhaled carbon monoxide in patients with interstitial lung disease is related to the degree of impairment of carbon monoxide diffusion capacity. Am J Respir Crit Care Med 1999; 159: A220.

29. Borland CD, Higenbottam TW. A simultaneous single breath measurement of pulmonary diffusing capacity with nitric oxide and carbon monoxide. Eur Respir $J$ 1989; 2: 56-63.

30. Piiper J, Schuster KD, Mohr M, Schulz H, Meyer M. Pulmonary diffusing capacity for carbon monoxide and nitric oxide. Adv Exp Med Biol 1988; 222: 491-495.

31. Chung SJ, Fung HL. Identification of the subcellular site for nitroglycerin metabolism to nitric oxide in bovine coronary smooth muscle cells. J Pharmacol Exp Ther 1990; 253: 614-619.

32. Body SC, Hartigan PM, Shernan SK, Formanek V, Hurford WE. Nitric oxide: delivery, measurement, and clinical application. J Cardiothorac Vasc Anesth 1995; 9: 748-763. 